\title{
Norovirus Infections Drop 49\% in the United States with Strict COVID-19 Public Health Interventions
}

\author{
Robert P. Lennon ${ }^{1}$, Christopher Griffin ${ }^{2}$, Erin L. Miller ${ }^{1}$, Huamei Dong ${ }^{3}$, David Rabago ${ }^{1}$, Aleksandra E. Zgierska ${ }^{1}$ \\ ${ }^{1}$ Penn State Health Milton S. Hershey Medical Center, Department of Family and Community Medicine, 700 HMC Drive, \\ Hershey, PA, 17033, USA, ${ }^{2}$ Pennsylvania State University, Applied Research Laboratory, North Atherton Street, State College, \\ PA, 16801, USA, ${ }^{3}$ Penn State Health Milton S. Hershey Medical Center, Department of Public Health Sciences, 700 HMC \\ Drive, Hershey, PA, 17033, USA
}

Correspondence: rlennon@pennstatehealth.psu.edu; Tel.: +1 904588 2621; Fax.: + 17175315024.

Received: 11 September 2020; Accepted: 11 December 2020

Data availability: De-identified data will be made available upon request of the corresponding author.

\begin{abstract}
Norovirus is a substantial burden on the U.S. We compared norovirus outbreaks before and during COVID-19. There were fewer norovirus outbreaks during COVID-19 compared to a similar time period in 2019 ( 326 versus 638, $\mathrm{P}<0.001$ ). Conclusion. COVID-19 public health interventions may be considered to decrease the burden of norovirus. This demonstrates the ability of more restrictive interventions to decrease other outbreaks of known or emerging viruses.
\end{abstract}

Key Words: Coronavirus • Norovirus • Public Health.

\section{Introduction}

Norovirus places a substantial burden on the U.S., with 19-21 million illnesses and 109,000 hospitalizations per year and an estimated annual cost of $\$ 6.2$ billion (inflation adjusted for 2020) $(1,2)$. Norovirus, like coronaviruses, can spread through person-to-person contact. Interventions to prevent COVID-19 infection should also decrease norovirus infection. Stay-at-home ("lockdown") orders to decrease the spread of COVID-19 were implemented in 32 states by 31 March, 2020 (3). There is evidence suggesting that COVID-19-related restrictions decreased influenza rates in the United States (R.P. Lennon, E.L. Miller, H. Dong, D. Rabago, A.E. Zgierska, unpublished data, August 2020). To our knowledge, the impact of COVID-19-related restrictions on norovirus infection rates has not been evaluated.

Our objective was to compare norovirus infection rates in the U.S. before and after COVID-19 lockdown.

\section{Materials and Methods}

Data from the Centers for Disease Control and Prevention (CDC), which collects norovirus outbreak data reported by health departments through the National Outbreak Reporting System (NORS), were used to compare weekly norovirus outbreak rates during the pre-COVID-19 2018-19 and 2019-20 seasons (August 1 through January 30) (4). In addition, weekly outbreaks rates after the COVID-19 lockdown (February 6 through June 6, 2020) were compared to the pre-COVID-19 rates (February 6 through June 6,2019$)$. This research is exempt per 45 CFR 46.101(b) (4). The differences in outbreak rates were assessed with a Wilcoxon signed rank test, with significance level established at two-tailed $\mathrm{P}<.05$, using $\mathrm{R}$ statistical software, Version 3.6.2.

\section{Results}

There were no significant differences $(\mathrm{P}=0.384)$ in pre-COVID-19 norovirus weekly outbreak rates 
between 2018-19 and 2019-2020 seasons through in 2020, compared to a similar time period in 2019 January 30, 2020 (Table 1). There were fewer noro- $\quad$ (326 versus 638, $\mathrm{P}<0.001$ ) (Table 1) virus weekly outbreaks post-COVID-19 lockdown

Table 1. Comparison of Norovirus Outbreaks Pre- and Post -COVID-19

\begin{tabular}{|c|c|c|c|c|}
\hline Weeks & Norovirus outbreaks* & Norovirus outbreaks ${ }^{\dagger}$ & Key events & Wilcoxon rank test, 2 -tailed to $95 \%$ confidence \\
\hline \multicolumn{5}{|c|}{ Pre-COVID-19 lockdowns in the United States } \\
\hline 1-Aug & 8 & 5 & - & \multirow{27}{*}{$\begin{array}{l}\text { Comparing outbreaks per week from August } \\
1,2019 \text { through January } 30,2020 \\
P=0.384\end{array}$} \\
\hline 8-Aug & 4 & 4 & - & \\
\hline 15-Aug & 5 & 2 & - & \\
\hline 22-Aug & 7 & 6 & - & \\
\hline 29-Aug & 7 & 11 & - & \\
\hline 5-Sep & 4 & 9 & - & \\
\hline 12-Sep & 11 & 11 & - & \\
\hline 19-Sep & 8 & 11 & - & \\
\hline 26-Sep & 6 & 12 & - & \\
\hline 3-Oct & 5 & 6 & - & \\
\hline $10-O c t$ & 13 & 10 & - & \\
\hline $17-$ Oct & 10 & 15 & - & \\
\hline 24-Oct & 11 & 12 & - & \\
\hline $31-O c t$ & 13 & 23 & - & \\
\hline 7-Nov & 12 & 25 & - & \\
\hline 14-Nov & 21 & 24 & - & \\
\hline 21-Nov & 40 & 17 & - & \\
\hline 28-Nov & 54 & 52 & - & \\
\hline 5-Dec & 62 & 48 & - & \\
\hline 12-Dec & 79 & 43 & - & \\
\hline 19-Dec & 36 & 48 & - & \\
\hline 26-Dec & 67 & 46 & - & \\
\hline 2-Jan & 81 & 59 & - & \\
\hline 9-Jan & 65 & 41 & - & \\
\hline 16-Jan & 56 & 46 & First U.S. case (5) & \\
\hline 23-Jan & 61 & 49 & - & \\
\hline 30-Jan & 48 & 57 & - & \\
\hline \multicolumn{5}{|c|}{ Post-COVID-19 lockdowns in the United States } \\
\hline 6-Feb & 53 & 55 & U.S. declares public health emergency (5) & \multirow{18}{*}{$\begin{array}{l}\text { Comparing outbreaks per week from February } \\
6,2020 \text { through June } 5,2020\end{array}$} \\
\hline 13-Feb & 50 & 48 & - & \\
\hline 20-Feb & 49 & 57 & - & \\
\hline 27-Feb & 68 & 61 & - & \\
\hline 6-Mar & 53 & 33 & - & \\
\hline 13-Mar & 49 & 34 & Lockdowns start (3) & \\
\hline 20-Mar & 51 & 13 & - & \\
\hline 27-Mar & 47 & 10 & 32 States in lockdown (3) & \\
\hline 3-Apr & 53 & 7 & - & \\
\hline 10-Apr & 32 & 1 & - & \\
\hline 17-Apr & 21 & 2 & - & \\
\hline 24-Apr & 18 & 1 & - & \\
\hline 1-May & 22 & 1 & - & \\
\hline 8-May & 27 & 0 & - & \\
\hline 15-May & 10 & 1 & - & \\
\hline 22-May & 16 & 2 & - & \\
\hline 29-May & 11 & 0 & - & \\
\hline 5-Jun & 8 & 0 & - & \\
\hline
\end{tabular}

"2018-2019; †2019-2020. 


\section{Discussion}

During the COVID-19-related lockdown period, the norovirus outbreak rates were lower than the year prior. Limitations of this comparison include potential changes in public care-seeking behaviors or physician testing patterns during the COVID-19 pandemic, and the NORS system approach to data collection, which relies on voluntary reports by health departments. Further, the 2020 norovirus data will not be finalized until 12-18 months after the end of the current season and, therefore, these estimates may still change.

\section{Conclusion}

The reductions in norovirus burden associated with COVID-19 restrictions suggest the power of restrictive public health measures to impact infectious disease burden more generally. Such measures may be considered for other high-burden outbreaks of known and emerging viruses now and in the future.

Author's Contributions: Conception and design: RL and CG; Acquisition, analysis and interpretation of data: RL, CG, EM, HD, DR and AZ; Drafting the article: RL and CG; Revising it critically for important intellectual content: RL, CG, EM, HD, DR and AZ; Approved final version of the manuscript: RL, CG, EM, HD, DR and AZ.

Conflict of Interest: The authors declare that they have no conflict of interest.

\section{References}

1. Centers for Disease Control and Prevention. Burden of Norovirus Illness in the U.S. [cited 2020 Jul 22]; Available from: https://www.cdc.gov/norovirus/trends-outbreaks/ burden-US.html.

2. Bartsch SM, Lopman BA, Hall AJ, Parashar UD, Lee BY. The potential economic value of a human norovirus vaccine for the United States. Vaccine. 2012;30(49):7097-04.

3. Higham A. US lockdown: When did the US go into lockdown?, in Express [Internet]. 2020, Express Newspapers PLC: London (UK). [cited 2020 Aug 15]; Available from: https://www.express.co.uk/news/world/1270061/USlockdown-When-did-the-US-go-into-lockdown.

4. Centers for Disease Control and Prevention (CDC). Norovirus Outbreaks Reported by State Health Departments by Week of Illness Onset, 2012-2019. [cited 2020 Jul 22]; Available from: https://www.cdc.gov/norovirus/reporting/norostat/data-table.html.

5. American Journal of Managed Care. A Timeline of COVID-19 Developments in 2020. [cited 2020 Aug 15]; Available from: https:/www.ajmc.com/view/a-timelineof-covid19-developments-in-2020. 